\title{
Erratum to: On Global Attractors of Multivalued Semiflows Generated by the 3D Bénard System
}

\author{
Alexey V. Kapustyan • Andrey V. Pankov • \\ José Valero
}

Published online: 24 February 2012

(C) Springer Science+Business Media B.V. 2012

\section{Erratum to: Set-Valued Anal \\ DOI 10.1007/s11228-011-0197-5}

In the paper [1] there is a mistake in the name of the second author. The correct name is Andrey V. Pankov.

\section{Reference}

1. Kapustyan, A.V., Pankov, A.V., Valero, J.: On global attractors of multivalued semiflows generated by the 3D Bénard system. Set-Valued Anal. doi:10.1007/s11228-011-0197-5

The online version of the original article can be found under http://dx.doi.org/10.1007/s11228-011-0197-5.

A. V. Kapustyan

Institute for Applied System Analysis NASU, NADOS Laboratory, Taras Shevchenko National University of Kyiv, Kyiv, Ukraine e-mail: alexkap@univ.kiev.ua

A. V. Pankov

Taras Shevchenko National University of Kyiv, Kyiv, Ukraine

e-mail: cold_flame@ukr.net

J. Valero $(\bowtie)$

Centro de Investigación Operativa,

Universidad Miguel Hernandez de Elche, 03202 Elche (Alicante), Spain

e-mail: jvalero@umh.es 